\title{
PROMOTING STUDENT ENGAGEMENT USING SOCIAL MEDIA TECHNOLOGIES
}

\author{
Mohammad Alshayeb \\ Information and Computer Science Department \\ King Fahd University of Petroleum \& Minerals \\ Dhahran 31261, Saudi Arabia
}

\begin{abstract}
Using social media in education provides learners with an informal way for communication. Informal communication tends to remove barriers and hence promotes student engagement. This paper presents our experience in using three different social media technologies in teaching software project management course. We conducted different surveys at the end of every semester to evaluate students' satisfaction and engagement. Results show that using social media enhances students' engagement and satisfaction. However, familiarity with the tool is an important factor for student satisfaction.
\end{abstract}

\section{KEYWORDS}

Student engagement, social media, instructional technology

\section{INTRODUCTION}

Instructors in higher education have been using different computer related technologies in education, such as multimedia [1, 2], communication [3] and mobile [4]to enhance students' learning. Different technologies have been utilized in the classroom environment such as blogs, wikis, portals, instant messaging, and Facebook [5-7].

Researchers reported that the use of technology and electronic media has improved teaching and learning process [8-11]. Babur [12]found that using technology in teaching helped students to increase their capability for understanding. Beichner et al. [13] also found that students taught with a technology-based approach outperformed and were more satisfied than students taught with the traditional teaching methods. Mobile technologies were also found to be effective in teaching and learning $[14,15]$. Barbosa et al. reported that the use of mobile in teaching improved the learning and the interaction between learners [16]. Game-based learning [17, 18] was also found to be effective in enhancing students' learning process. However, other researchers found that technology may have negative effects [19-24].

Student engagement is important for students' performance, retention and achievement [25]. Manwaring et al. [26] investigated student engagement in blended learning classes. Gunuc and Kuzu [25] conducted a study to evaluate the impact of technology on student engagement and to 
find the relationships between student engagement and technology use in class. They found that the use of technology in and out the class increased student engagement. Bray and Tangney [4] explored the impact of using mobile technologies in students' engagement; they found that the use of mobile technologies increases student engagement.

Social media tools provide interactive environment for communication. Computer communication methods not only should be usable, but they should also be engaging [27]. Dyson et al. [28] conducted an experiment with a large-scale class in which two-thirds of the class were supposed to use Facebook and one-third without. They found that students who did not view the Facebook postings reported lower engagement and understanding of the in-class discussion. Rashid and Asghar [29] conducted a study to evaluate the impact of technology use in student engagement. They found that the use of technology has a direct positive relationship with students' engagement. Imlawi et al. [30] reported that students are more engaged, motivated and satisfied when the instructor uses course-based online social networks to communicate with them.

In this paper, the researcher evaluates students' engagement when using three different social media technologies. The researcher first started by using Facebook for four years; during these four years, students reported that they were motivated and engaged, however, students after the four years, started to report that Facebook is not appropriate for communication and hence engagement has been reduced. Based on their recommendation and the instructor's evaluation, WhatsApp is used to replace Facebook. WhatsApp was used successfully for one year were students were positive about its use, however, due to the need for personalized communication, Slack [31] tool was selected. Results are promising, even though students were more satisfied in WhatsApp than Slack, yet they have shown interest and satisfaction.

The reminder of this paper is organized as follows: Section 2 describes the course and the communication objectives. Section 3 presents the rational for selecting the used tools. The evaluation and discussion of student engagement and satisfaction is presented in section 4 . Finally, section 5 presents the conclusion and the future work.

\section{COURSE DESCRIPTION AND COMMUNICATION OBJECTIVES}

In this section, we discuss the course description and the objectives of using different social media technologies to promote students' engagement.

\subsection{Course Description}

Using technology in a course should serve the course objective. An important course objective in the software project management course is enhancing communication. The availability of software technology tools can help in achieving this objective. Software project management is a core course in the software engineering program at King Fahd University of Petroleum and Minerals (KFUPM) and can be taken as an elective for other students in other disciplines. Students are required to do a project and three homework assignments that require teamwork and hence good communication skills is required. In addition, the project and the assignments require lots of interaction with the course instructor. All students registered in the course are from IT background (software engineering, computer science and computer engineering) and hence it is easy to use software technologies. 


\subsection{Objectives of using Communication Tools}

As indicated earlier, the course requires lots of communication among the students themselves and between the instructor and the students. The following are the different communication objectives have been achieved by using social media technologies:

- Course Announcements: Posting course announcement for quick dissemination. This includes all announcements related to the course such as homework deadlines and change in the plan etc.

- Discussion Questions by the Instructor: Posting questions for discussion for students. Since most students are often online, many of them participated effectively.

- Discussion Questions by the Students: To motivate effective problem solving and team work, each team was assigned for one week the responsibility for answering all the questions posted. This new twist encouraged students to ask/answer the discussion questions.

- Chat/Virtual Office Hours: Before the exam, online office hours session was conducted so that students can chat with the instructor to answer their questions.

- Response to Urgent Queries: since the social media are accessible anywhere any time, this enabled quick response to all students' queries no delay especially before the submission deadlines.

\section{SOCIAL TOOL SELECTION}

The use of social media technologies in my classes was started in 2011 by using Facebook. The selection of Facebook was based on my evaluation of the appropriate tool in addition to students' request. At the end of every semester, the course instructor conduct a survey to evaluate students' engagement and satisfaction of using the technology. In 2014 survey, most students indicated that the Facebook is not appropriate to be used anymore, specific students; comments are listed below:

- Unfortunately, Facebook is dying in our region and I only open it for this group

- I do not recommend Facebook in the next offering

- To me, the use of Facebook was really a bad experience

- It is better to use technology other than Facebook

- $\quad$ NOT using Facebook

- It was hard for me to check on Facebook, also using WhatsApp group could be a good and faster way 
After this feedback and based on my evaluation for appropriate tools, the course instructor stopped using Facebook and started using WhatsApp in 2014. Even though WhatsApp use was successful, there was a need for personalized team communication which is not supported by WhatsApp. Hence, it was decided to search for a more appropriate technology and started to use Slack [31] as a new method for communication.

\section{EVALUATION}

As indicated in section 3, at the end of each semester, the course instructor conduct a survey to evaluate student's engagement and satisfaction. The details of surveys to evaluate these social media technologies are discussed in the following subsections.

\subsection{Facebook}

Facebook was first used in my classes in 2011. The details of the survey that evaluate the use of Facebook are discussed in this section. In response to question "The use of Facebook for class communication was effective and useful and enhanced my learning experience", $95 \%$ of the students either strongly agree or agree that using Facebook for class communication was effective and useful and enhanced their learning experience as shown in Figure 1.In response to a question "Which technologies, used in the course, improved your learning the most?", 15 students out of 22 selected Facebook.

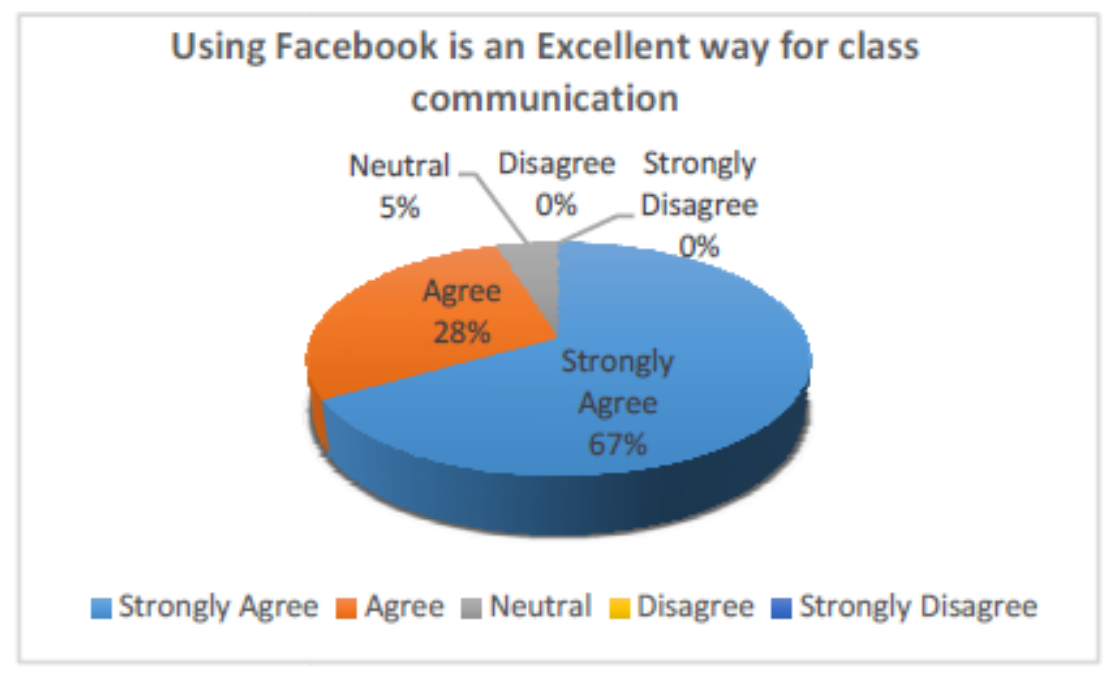

Figure 1 : Using Facebook for communication

Figure 3 shows that $83 \%$ of the students either strongly agree or agree that discussion questions posted on that WhatsApp group were useful. 


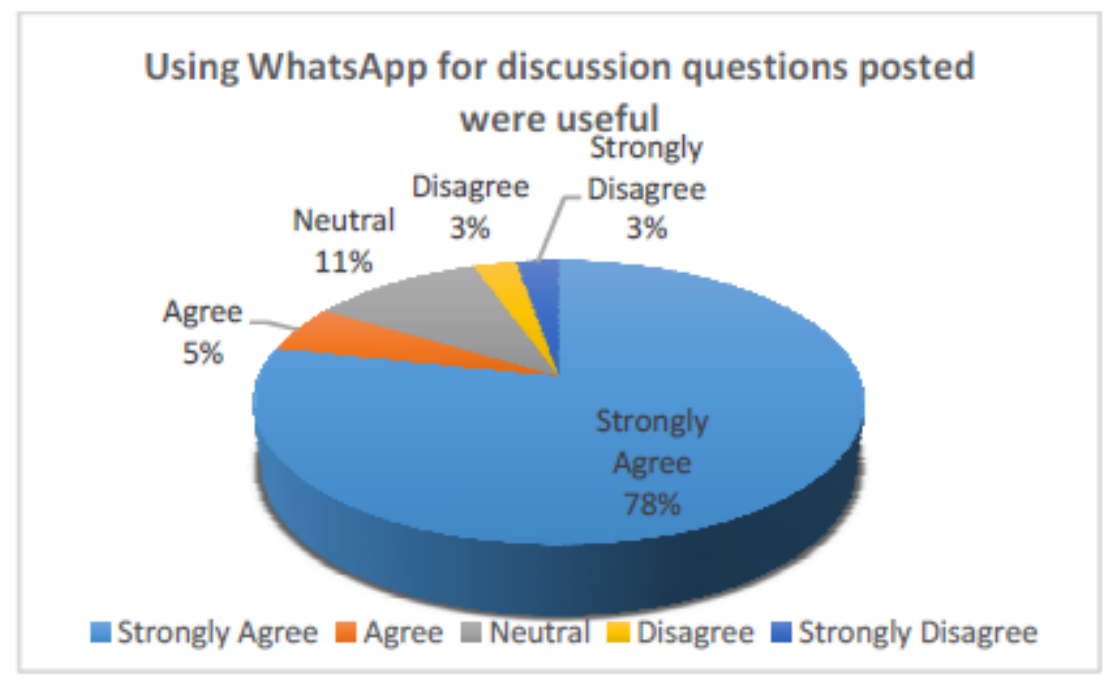

Figure 3. Using WhatsApp for discussion questions

Figure 4 shows that $87 \%$ of the students recommend using WhatsApp in the future offering of the course.

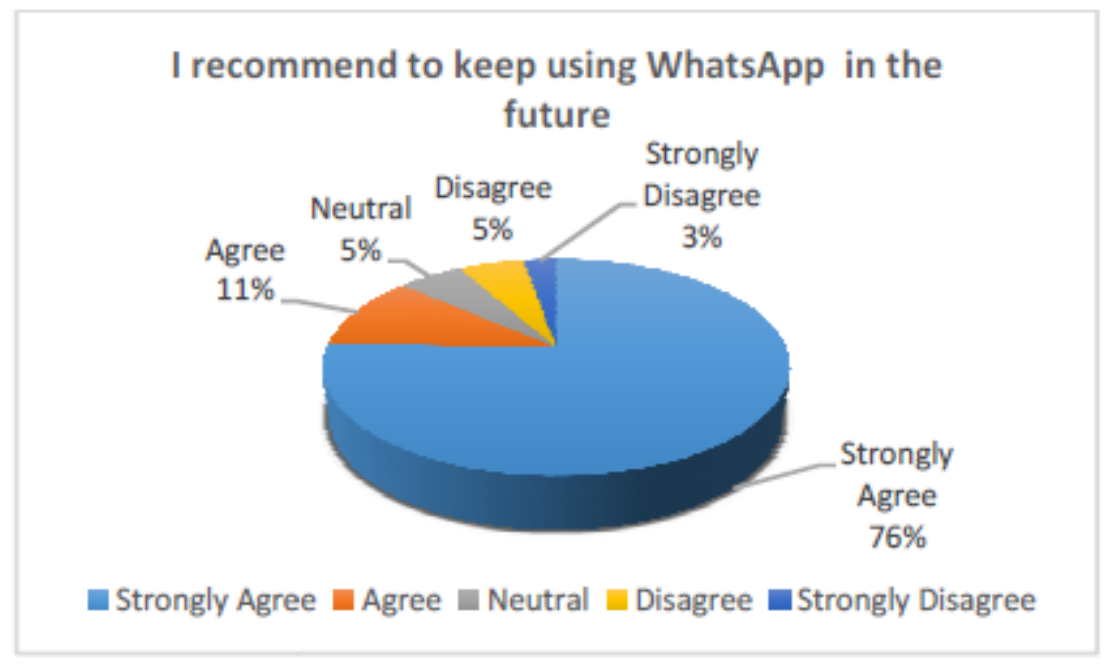

Figure 4. Recommending using WhatsApp in the Future

Even though students were engaged and satisfied by using WhatsApp, there was a need personalized team communication; to do that in WhatsApp, a group for each team should be created which is not convenient. Hence, the instructor searched for an alternative tool to be used and selected Slack.

\subsection{Slack}

Slack is a tool that is mainly used to manage projects. For communication, it has all features of WhatsApp, in addition it can have a personalized channel for teams' communicaiton. Furthermore, a wide number of tools can be integrated with Slack. Therefore, slack was selected 
mainly for the personalized communication. Slack was used so far for one semester; a survey was conducted in 2018. Figure 5 shows the student response for using slack as a communication method. $65 \%$ of the students agree or strongly agree that using slack is an excellent way of communication. This percentage is less than for WhatsApp. When investigating the reasons for that, students reported that this is the first time of using slack, therefore they are not familiar with it.

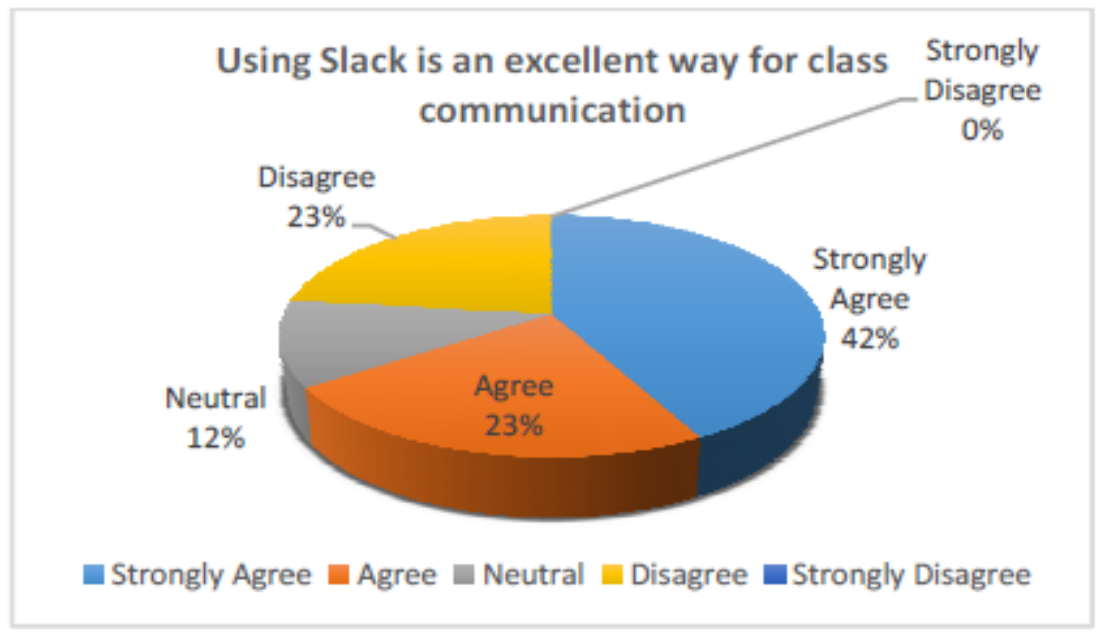

Figure 5. Communication Using Slack

\subsection{Technology Use}

In addition to the surveys for the social media technologies, questions on using technology in general are asked to the students. In 2011, in response to the question "Using technology in teaching this course enhanced my learning experience". Figure 6 shows that $100 \%$ of the students either strongly agree or agree that using technology in teaching this course enhanced their learning experience.

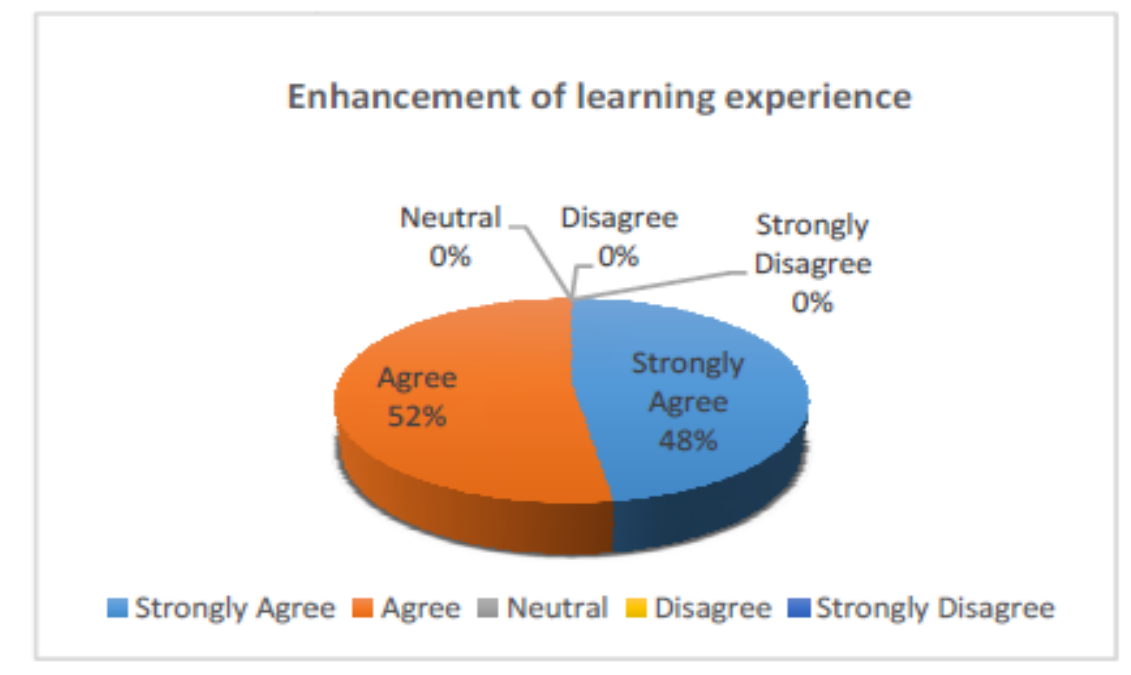

Figure 6: Using technology in enhancing the learning experience 
In 2015, the survey included more questions to evaluate students' engagement and satisfaction In response to the question: "The use of technology made the course more interesting", $100 \%$ of the students either strongly agree or agree that using technology in the course made the course more interesting as shown in Figure 7.

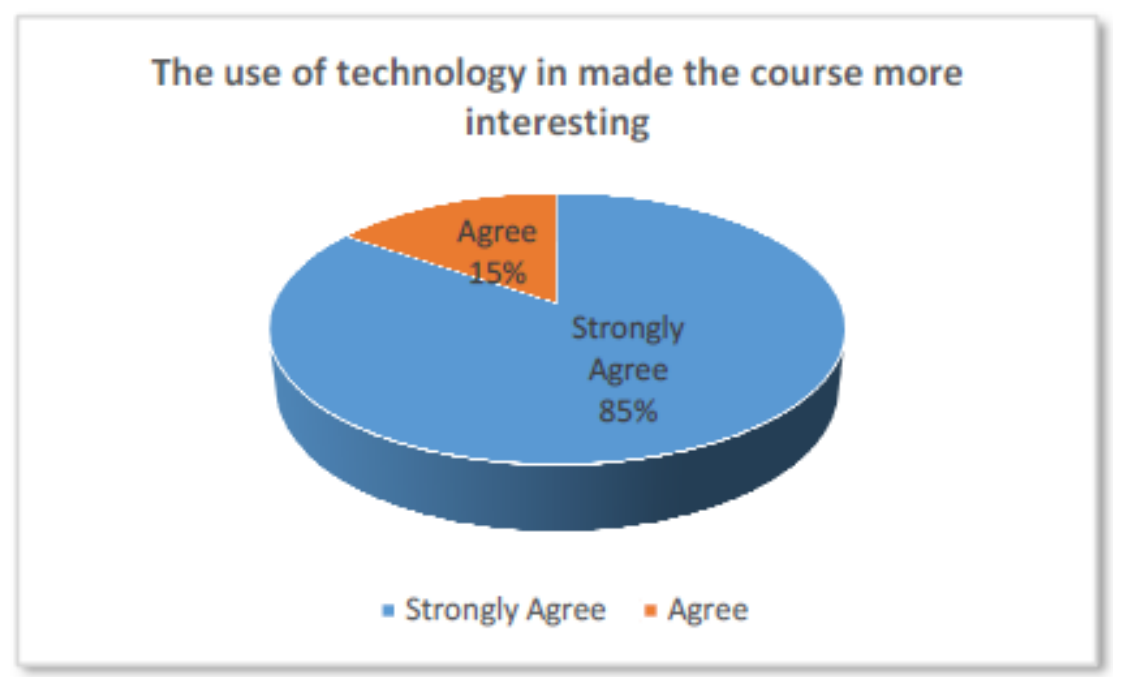

Figure 7: The use of technology in made the course more interesting

In response to the question: "The use of technology made me more interested in the course", $100 \%$ of the students either strongly agree or agree that using technology in the course made them more interested in the course as shown in Figure 8.

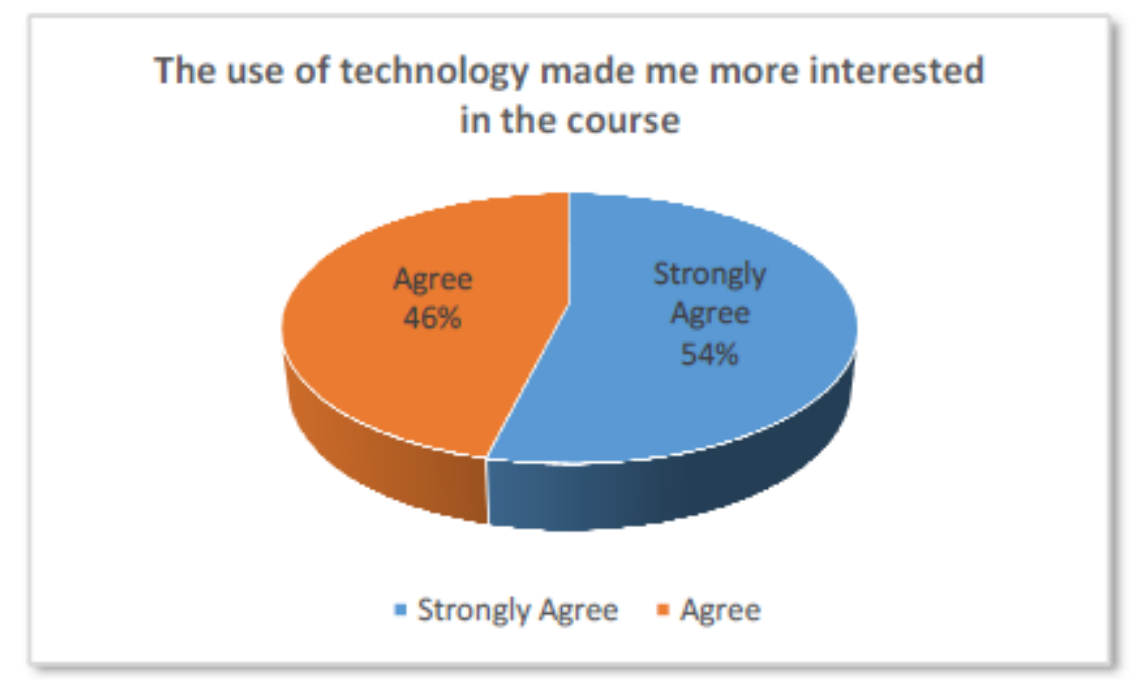

Figure 8: The use of technology and interest in the course

$92 \%$ of the students either strongly agree or agree that using technology in the course enabled effective communications among students as shown in Figure 9. 


\section{The use of technology enabled effective communications among the students}

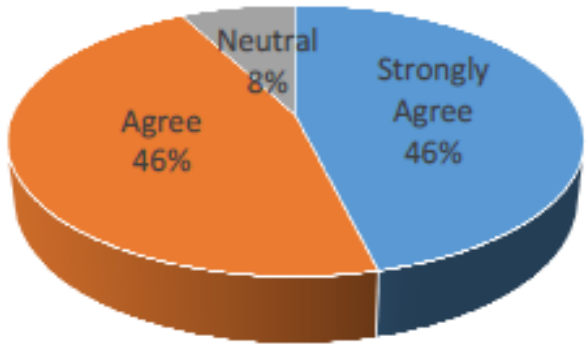

- Strongly Agree "Agree " Neutral

Figure 9: The use of technology and effective communications among students

$100 \%$ of the students either strongly agree or agree that using technology in the couse enabled effective communication between the students and the instructor as shwon in Figure 10.

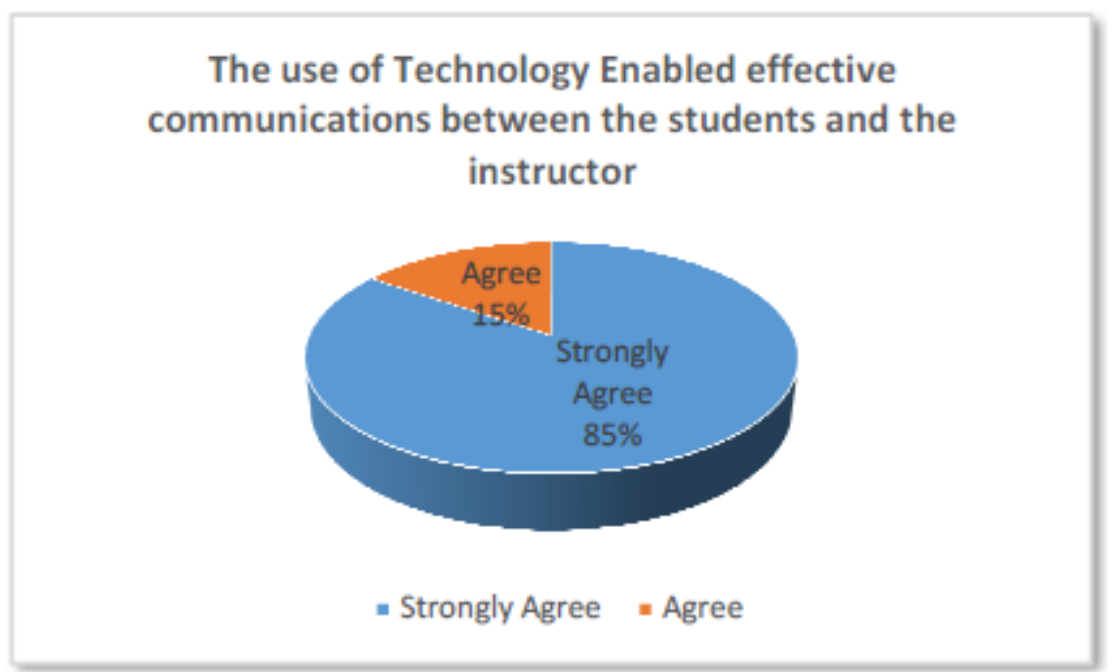

Figure 10: The use of technology enabled effective communications between the students and the instructor

$100 \%$ of the students strongly agree recommend using different technologies in the future offering of the course as shown in Figure 11. 


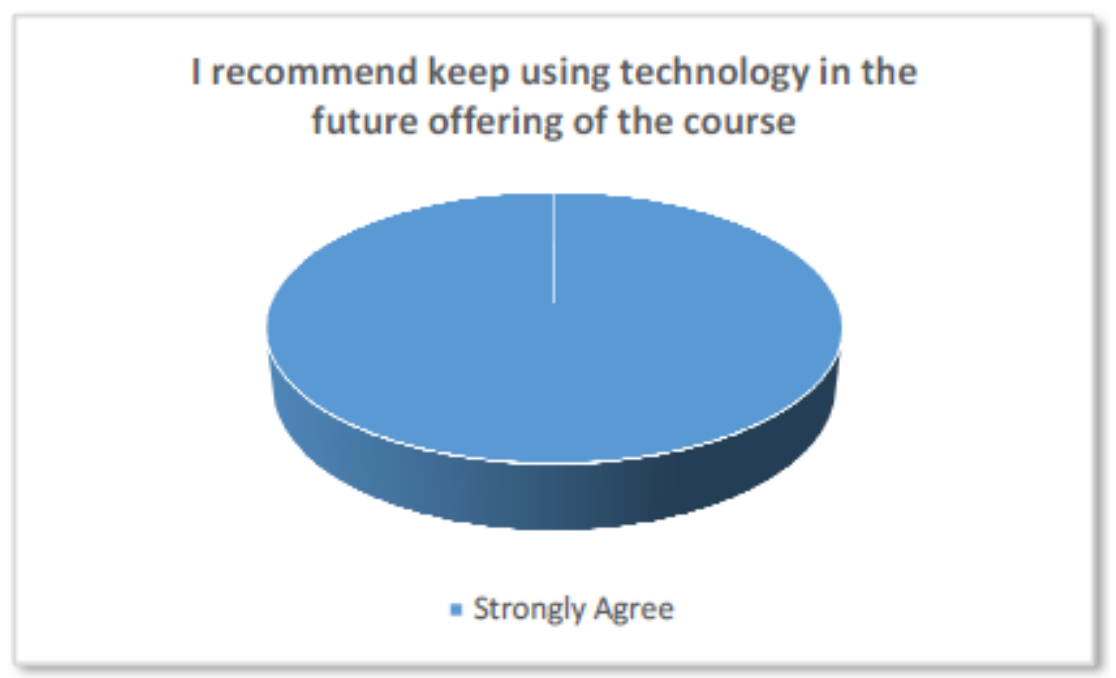

Figure 11: Recommendation of using technology in the future

\subsection{Benefits of using Social Media Technologies}

Using the above mentioned social media technologies provided a better students' learning experience and promoted students' engagement. This can be attributed to many reasons as these tools : 1) enhanced the communication between the instructor and students and among students, 2) extended the communication for more than the lecture time, 3) provided the students with a convenient way to ask and answer discussion questions, finally, 4) created a referable record of course discussions. In addition, they helped the instructor to identify concepts that need further discussion and helped in enhancing critical thinking by students.

\section{CONCLUSION}

Social media tools provide interactive environment for communication. This paper presents our experience in using three different social media technologies to enhance students' engagement. We presented our experience with using Facebook for four years then moved to use WhatsApp based on students' request and the instructor's evaluation. Finally, Slack tool was used as a new method for communication.

Our results show that the three methods were found to be effective in promoting students' engagement. However, students seem to be less satisfied when using Slack. This is attributed to the fact that most students never used it before and hence they were not familiar with it, yet, majority were satisfied.

In our future studies, we plan to evaluate the impact of students' performance in using social media tools and technologies, in addition, we plan to evaluate the impact of using gamification technologies in students' engagement and performance.

\section{ACKNOWLEDGEMENT}

The authors acknowledge the support of King Fahd University of Petroleum and Minerals. 


\section{REFERENCES}

[1] E. Cutrim Schmid, "Potential pedagogical benefits and drawbacks of multimedia use in the English language classroom equipped with interactive whiteboard technology, "Computers \& Education, vol. 51, no. 4, pp. 1553-1568, 2008

[2] L. Proserpio and D. Gioia, "Teaching the virtual generation," Academy of Management Learning and Education, vol. 6, no. 1, pp. 69-80, 2007.

[3] M. Alavi and R. B. Gallupe, "Using Information Technology in Learning: Case Studies in Business and Management Education Programs," Academy of Management Learning \& Education, vol. 2, no. 2, pp. 139-153, 2003.

[4] A. Bray and B. Tangney, "Enhancing student engagement through the affordances of mobile technology: a 21st century learning perspective on Realistic Mathematics Education,"Mathematics Education Research Journal, journal article vol. 28, no. 1, pp. 173-197, March 01, 2016

[5] S. L. Connell, "Comparing blogs, wikis, and discussion boards as collaborative learning tools," in "In Wiki, Hyderabad: India: ICFAI (the Institute of Financial Analysts of India) University Press, "2006.

[6] J. Farmer, "Communication dynamics: Discussion boards, weblogs and the development of communities of inquiry in online learning environments," in Conference of the Australasian Society for Computers in Learning in Tertiary Education, 2004, pp. 1-10.

[7] D. Fichter, "The many forms of e-collaboration: Blogs, wikis, portals, groupware, discussion boards, and instant messaging," Trade Publication, vol. 29, no. 4, pp. 48-50, 2005.

[8] E.-S. Aziz, "Teaching and Learning Enhancement in Undergraduate Machine Dynamics,"Computer Applications in Engineering Education, vol. 19, no. 2, pp. 244-255, 2011.

[9] E. Y. Borkowski, D. Henry, L. L. Larsen, and D. Matelik, "Supporting teaching and learning via web: Transforming hard-copy linear mind sets into web flexible creative thinking," Journal of Network Computer Application, vol. 20, pp. 253-265, 1997.

[10] A. F. Grasha and H. N. Yangarber, "Integrating teaching styles and learning styles with instructional technology," College Teaching, vol. 48, no. 1, pp. 2-9, 2009.

[11] A. K. Aggarwal and R. Bent, "Web based education, In learning and teaching Technologies,"WebBased Opportunities and Challenges, pp. 2-16, 2000.

[12] B. Deliktas, "Computer technology for enhancing teaching and learning modules of engineering mechanics," Computer Applications in Engineering Education, vol. 19, no. 3, pp. 421-432, 2011.

[13] R. Beichner et al., "Case study of the physics components of an integrated curriculum. ,"American Journal of Physics, vol. 67, pp. S16-S24, 1999.

[14] C. Romero, S. Ventura, and P. d. Bra, "Using mobile and web-based computerized tests to evaluate university students," Computer Applications in Engineering Education, vol. 17, no. 4, pp. 435-447, 2009.

[15] G. Vavoula and M. Sharples, "Challenges in evaluating mobile learning," in Proceedings of the mLearn 2008 Conference, Shropshire, United Kingdom, 2008. 
[16] J. L. V. Barbosa, R. Hahn, D. N. F. Barbosa, and W. Segatto, "Intensive use of mobile technologies in a computer engineering course," Computer Applications in Engineering Education, 2012.

[17] W. R. Watson, C. J. Mong, and C. A. Harris, "A case study of the in-class use of a video game for teaching high school history," Computers \& Education, vol. 56, no. 2, pp. 466-474, 2011.

[18] M. Ebner and A. Holzinger, "Successful implementation of user-centered game based learning in higher education: An example from civil engineering," Computers \& Education, vol. 49, no. 3, pp. $873-890,11 / / 2007$.

[19] V. K. G. Lim, "The IT way of loafing on the job: Cyberloafing, neutralizing and organizational justice," Journal of Organizational Behavior, vol. 23, no. 5, pp. 675-694, 2002.

[20] M. J. Austin and L. D. Brown, "Internet plagiarism: Developing strategies to curb student academic dishonesty," The Internet and Higher Education, vol. 2, no. 1, pp. 21-33, 1999.

[21] D. L. McCabe, K. D. Butterfield, and L. K. Trevio o, "Academic dishonesty in graduate business programs: Prevalence, causes, and proposed action," Academy of Management learning and Education, vol. 5, no. 3, pp. 294-305, 2006.

[22] R. E. Mayer, J. Heiser, and S. Lonn, "Cognitive constraints on multimedia learning: When presenting more materials results in less understanding," Journal of Educational Psychology, vol. 93, no. 1, pp. 187-198, 2001.

[23] S. C. Rockwell and L. A. Singleton, "The effect of the modality of presentation of streaming multimedia on information acquisition," Media Psychology, vol. 9, no. 1, pp. 179-191, 2007.

[24] C. Chou, "Internet Heavy Use and Addiction among Taiwanese College Students: An Online Interview Study," CyberPsychology \& Behavior, vol. 4, no. 5, pp. 573-585, 2004.

[25] S. Gunuc and A. Kuzu, "Confirmation of Campus-Class-Technology Model in student engagement: A path analysis," Computers in Human Behavior, vol. 48, pp. 114-125, 2015/07/01/2015.

[26] K. C. Manwaring, R. Larsen, C. R. Graham, C. R. Henrie, and L. R. Halverson, "Investigating student engagement in blended learning settings using experience sampling and structural equation modeling," The Internet and Higher Education, vol. 35, pp. 21-33, 2017/10/01/ 2017.

[27] H. L. O'Brien and E. G. Toms, "The development and evaluation of a survey to measure user engagement," Journal of the Association for Information Science and Technology, vol. 61, no. 1, pp. $50-69,2010$.

[28] B. Dyson, K. Vickers, J. Turtle, S. Cowan, and A. Tassone, "Evaluating the use of Facebook to increase student engagement and understanding in lecture-based classes," Higher Education, journal article vol. 69, no. 2, pp. 303-313, February 012015.

[29] T. Rashid and H. M. Asghar, "Technology use, self-directed learning, student engagement and academic performance: Examining the interrelations," Computers in Human Behavior, vol. 63, pp. 604-612, 2016/10/01/ 2016.

[30] J. Imlawi, D. Gregg, and J. Karimi, "Student engagement in course-based social networks: The impact of instructor credibility and use of communication," Computers \& Education, vol. 88, pp.84$96,2015 / 10 / 01 / 2015$.

[31] Slack. Available: https://slack.com/ 